\title{
FUZZY SYSTEMS TO SUPPORT INDUSTRIAL ENGINEERING MANAGEMENT
}

\author{
Dr Isabel L. Nunes * \\ Universidade Nova de Lisboa, Faculty of Science and Technology, Portugal
}

This paper presents the potentialities of Fuzzy Set Theory to deal with complex, incomplete and/or vague information which is characteristic of some industrial engineering problems. Two systems that were developed to support the activities of industrial engineering managers are presented as examples of the use of this mathematical methodology.

Key words: Work related musculoskeletal disorders, Ergonomics, Resilience, Supply chain, disturbances, Industrial engineering, Fuzzy systems

\section{INTRODUCTION}

Many problems in Industrial Engineering are complex and have incomplete and/or vague information. Also the dynamics of the decision environment limit the specification of model objectives, constraints and the precise measurement of model parameters (Kahraman et al., 2006). Fuzzy Set Theory (FST) developed almost fifty years ago by L.A. Zadeh (Zadeh, 1965), is an excellent framework to help solve these problems. According to (Kahraman, 2006) Industrial Engineering is one of the branches where FST found a wide application area. (Kahraman et al., 2006) present an extensive literature review and survey of FST in Industrial Engineering. A review of the application of FST to human-centred systems can be found in (Nunes, 2010).

This paper presents two application examples of fuzzy decision support systems aiming to support industrial engineering managers in two different areas of risk management: ergonomics and supply chain disturbances management.

\section{FUZZY SET THEORY}

FST provides the appropriate logical/mathematical framework to deal with and represent knowledge and data, which are complex, imprecise, vague, incomplete and subjective (Zadeh, 1965). It allows the elicitation and encoding of imprecise knowledge, providing a mean for mathematical modeling of complex phenomena where traditional mathematical models are not possible to apply.

A fuzzy set (FS) is the generalization of classical (crisp) set. By contrast with classical sets which present discrete borders, FS presents a boundary with a gradual contour. Formally, let $U$ be the universe of discourse and $u$ a generic element of $U$, a fuzzy subset $A$, defined in $U$, is a set of dual pairs:

$$
A=\left\{\left(u, \mu_{A}(u)\right) \mid u \in U\right\}
$$

where $\mu_{A}(u)$ is designated as membership function or membership grade $u$ in A. The membership function associates to each element $\mathrm{u}$, of $\mathrm{U}$, a real number $\mu_{A}(u)$, in the interval $[0,1]$, which represents the degree of truth that $u$ belongs to $A$.

Using FST it is possible to evaluate the degree of membership of some observed data, originating either from an objective source or a subjective source, to some high-level concept. Let us consider, for example, the evaluation of the delay disturbance based on the continuous membership function presented in Figure. A low degree of membership to the disturbance concept (i.e., values close to 0) means the delay is acceptable; while a high degree of membership (i.e., values close to 1) means the delay is unacceptable (Nunes \& Cruz-Machado, 2012).

The human-like thinking process, i.e., approximate reasoning is well modeled using Fuzzy Logic (FL), which is a multi-value logic concept based on FST (Zadeh, 1996). Thus FL permits to process incomplete data and provide approximate solutions to problems that cannot be solved by traditional methods. It allows handling the concept of partial truth, where the truth value may range between completely true and completely false. Furthermore, when Linguistic Variables (LV) are used, these degrees may be managed by membership functions (Zadeh, 1975a; 
1975b; 1975c). A LV is a variable that admits as values words or sentences of a natural language (Figure 2), their terms can be modified using linguistic hedges (modifiers) applied to primary terms.

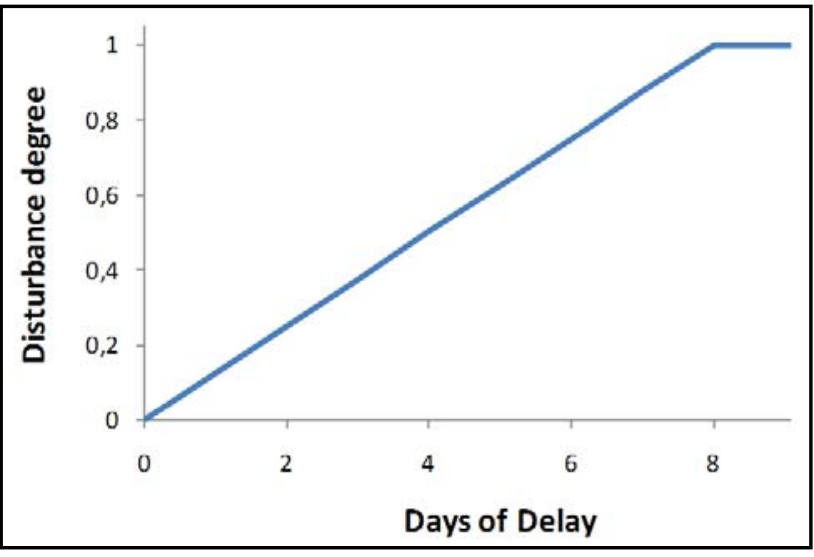

Figure 1: Fuzzy set delay disturbance

(Nunes \& Cruz-Machado, 2012)

FST can be used in the development of, for instance, fuzzy expert systems or fuzzy decision support systems. The following cases are examples of these types of systems that can support industrial engineering managers' activities.

\section{EXAMPLES OF FUZZY SYSTEMS FAST ERGO $X$}

Work-related musculoskeletal disorders (WMSD) are diseases related and/or aggravated by work that can affect the upper and the lower limbs as well as the neck and lower back areas. WMSD can be defined by impairments of bodily structures such as muscles, joints, tendons, ligaments, nerves, bones and the localized blood circulation system, caused or aggravated primarily by work itself or by the work environment (Nunes \& Bush, 2012).



Figure 2: Linguistic variable inadequacy used to evaluate "protection inadequacy" (Nunes \& Simões-Marques, 2012)
FAST ERGO X (Figure 3) is a fuzzy expert system designed to identify, evaluate and control the risk factors existing in a work situation, due to lack of adequate ergonomics that can lead to the development of WMSD (Nunes, 2006; Nunes, 2009).

Fast Ergo $X$ evaluates the risk factors based on objective and subjective data and produce results regarding the degree of possibility of development of WMSD on the upper body joints and about the main contributing risk factors. The results (Conclusions) are presented both quantitatively (as membership degrees to inadequacy fuzzy set, defined in the interval $[0,1]$ ) and qualitatively (as terms of a linguistic variable intensity). For instance "The possibility for development of a WMSD on the Right Wrist is extreme (0.92)". The Conclusions can be explained (Explanations) by presenting the computed risk factors inadequacy degrees that contributed to the overall result, e.g. "The number of Repetitions performed by the Right Wrist is very high". The system also presents Recommendations that users can adopt to eliminate or at least to reduce the risk factors present in the work situation. Some of the recommendations are in the form of good practices and graphical illustrations.

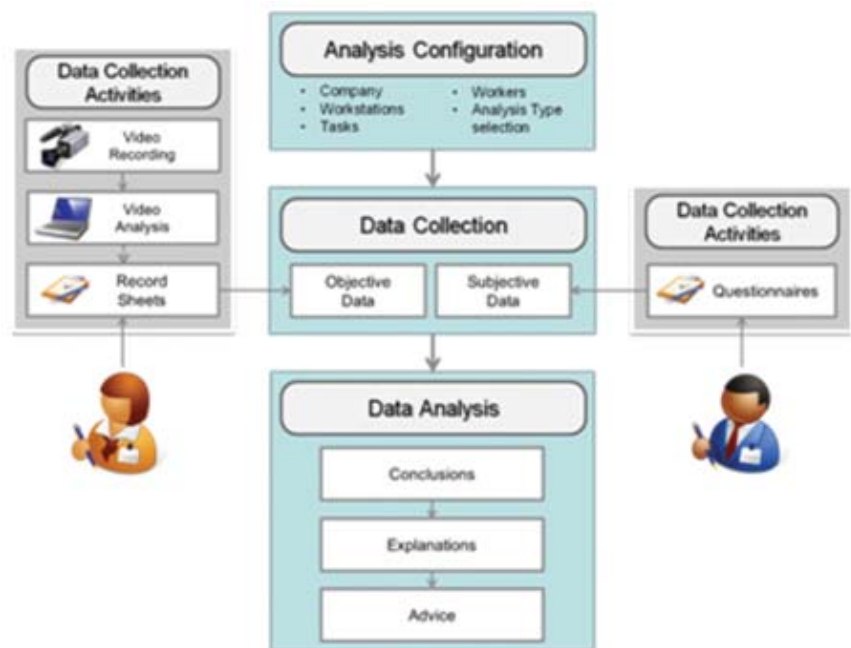

Figure 3: Activities performed on the analysis of a work situation by FAST ERGO X (Nunes, 2009)

\section{A Fuzzy Decision Support System to manage supply chain disturbances}

Supply Chains (SC) are subject to disturbances that can result from acts or events that are originated inside of the SC (e.g., supplier failures, equipment breakdown, employees' absenteeism) or may result from extrinsic events (e.g., social turmoil, terrorist attacks, or acts of God such as volcanic eruptions, hurricanes or earthquakes) 
(Nunes \& Cruz-Machado, 2012). The Supply Chain Disturbance Management Fuzzy Decision Support System (SCDM FDSS) developed by (Nunes et al., 2011) was designed to assess the SC and the organizations belonging to the $\mathrm{SC}$ based on their performance considering the following different scenarios, normal operation, when a disturbance occurs and when mitigation and/or contingency plans are implemented to counter the disturbance. The aim of the SCDM FDSS is to assist managers in their decision process related with the choice of the best operational policy (e.g., adoption of mitigation and/or contingency plans) to counter disturbance effects that can compromise SC performance.

The system combines the use of FST to model the uncertainty associated with the disturbances and their effects on the SC with the use of discrete-event simulations using the ARENA software (a commercial simulation tool) to study the behavior of the SC subject to disturbances, and the effects resulting from the implementation of mitigation or contingency plans. The block diagram of the proposed SCDM FDSS is illustrated in Figure 4.



Figure 4: Relationship between SCDM FDSS and ARENA (adapted from (Nunes et al., 2011)).

The Inference Engine offers the reasoning capability of the system. It performs the FDSS analysis using a Fuzzy Multiple Attribute Decision Making model, and fuzzy data that characterizes the analyzed situation, using for instance fuzzified Key Performance Indicators (KPI). The inference process includes 7 steps (Nunes et al., 2011):

1. Computing the KPI for each scenario and SC entity for each simulation time period. The $\mathrm{KPI}$ are obtained at the end of each ARENA SC simulation;

2. Synthesizing the time discrete KPI into an equivalent $\mathrm{KPI}$ for the relevant period considered (obtained through a mean function);

3. Fuzzifying the equivalent $\mathrm{KPI}$ into a fuzzy KPI (FKPI). Fuzzy sets convert KPI in normalized $F K P I$, i.e., fuzzy values in the interval $[0,1]$, where a fuzzy value close to 0 means a bad performance and a fuzzy value close to 1 means a good performance;

4. Computing of a fuzzy performance Category Indicator $(\mathrm{Cl})$ for each scenario and SC entity using weighted aggregations of FKPI, through the following expression:

$$
C I_{i k}=\sum_{j=1}^{n} w_{i j k} \times F K P I_{i j k}
$$

where:

$\mathrm{Cl}_{\mathrm{ik}}$ - is the fuzzy performance Category Indicator for $\mathrm{i}^{\text {th }}$ category of KPI and for $\mathrm{k}^{\text {th }} \mathrm{SC}$ entity;

$\mathrm{FKPI}_{i \mathrm{ijk}}$ - is the $\mathrm{j}^{\text {th }}$ Fuzzy Key Performance Indicator of the $\mathrm{i}^{\text {th }}$ category of $\mathrm{KPI}$ and the $\mathrm{k}^{\text {th }} \mathrm{SC}$ entity;

$\mathrm{w}_{\mathrm{ijk}}$ - is the weight of $\mathrm{j}^{\text {th }}$ Fuzzy Key Performance Indicator of the $\mathrm{i}^{\text {th }}$ category of KPI and the $\mathrm{k}^{\text {th }} \mathrm{SC}$ entity.

5. Computing of a fuzzy Performance Index (PI) for each scenario and SC entity using a weighted aggregation of $\mathrm{Cl}$, using the following expression:

$$
P I_{k}=\sum_{i=1}^{m} w_{i j k} \times C I_{i k}
$$

where:

$\mathrm{PI}_{\mathrm{k}}$ - is the Performance Index of $\mathrm{k}^{\text {th }} \mathrm{SC}$ entity; $\mathrm{Cl}_{\mathrm{ik}}$ - is the fuzzy performance Category Indicator for ith category of KPI and for $k^{\text {th }} \mathrm{SC}$ entity; $\mathrm{w}_{\mathrm{ijk}}$ - is the weight of the ith category of KPI and the $k^{\text {th }} S C$ entity.

6. Computing of a fuzzy Supply Chain Performance Index (SCPI) for each scenario using a weighted aggregation of PI, using the following expression:

$$
S C P I=\sum_{k=1}^{p} w_{k} \times P I_{k}
$$

where:

SCPI - is the Supply Chain Performance Index of the SC for the current scenario;

$\mathrm{PI}_{\mathrm{k}}$ - is the Performance Index of $\mathrm{k}^{\text {th }} \mathrm{SC}$ entity for the current scenario;

$\mathrm{w}_{\mathrm{k}}$ - is the weight of the $\mathrm{k}^{\text {th }} \mathrm{SC}$ entity.

7. Ranking alternatives. Scenario results for each entity and for the SC are ranked based on their PI and SCPI, respectively, in order to identify the operational policy with more merit. 
Using the results produced by the system ( $\mathrm{PI}$ and SCPI) managers can: forecast the effects of disturbances in SC entities and on a SC as a whole; analyze the reduction of the negative impacts caused by the disturbance when operational policies are implemented; and selecting the operational policy that makes the SC more resilient. The best operational policy corresponds to the implementation that leads to the highest PI/SCPI value.

The use of fuzzy modeling and simulation offers several benefits, inter alia, promotes a proactive SCDM, and improves the understanding of the impact of applying different operational policies meant to prevent or counter the effects of disturbances, allowing the selection of the ones that are more effective and efficient.

\section{CONCLUSIONS}

FST has been used since the sixties as a way to deal with complex, imprecise, uncertain and vague data in different areas of industrial engineering.

In this paper the main characteristics and advantages of the use of FST were highlighted. Two examples of fuzzy systems applied to support decision-makers in the industrial engineering context were very briefly presented (one in the field of ergonomics and other in the field of supply chains' management).

The objective was to raise awareness to the industrial engineers present in this conference to the potential that FST offers as a modelling tool to address complex phenomena that many industrial problems present.

\section{REFERENCES}

1) Kahraman, C. (2006). Preface. In: Fuzzy Applications in Industrial Engineering, C. Kahraman (ed). Springer, New York

2) Kahraman, C., Gülbay, M. \& Kabak, Ö. (2006). Applications of Fuzzy Sets in Industrial Engineering: A Topical Classification In: Fuzzy Applications in Industrial Engineering, C. Kahraman (ed). pp. 1-55. Springer, New York

3) Nunes, I. L. (2006). ERGO_X - The Model of a Fuzzy Expert System for Workstation Ergonomic Analysis. In: International Encyclopedia of Ergonomics and Human Factors, W. Karwowski (ed). pp. 3114-3121. CRC Press, ISBN 041530430X.
4) Nunes, I. L. (2009). FAST ERGO_X - a tool for ergonomic auditing and work-related musculoskeletal disorders prevention. WORK: A Journal of Prevention, Assessment, \& Rehabilitation, 34(2): pp. 133-148.

5) Nunes, I. L. (2010). Handling Human-Centered Systems Uncertainty Using Fuzzy Logics - A Review. The Ergonomics Open Journal, 3: pp. 38-48.

6) Nunes, I. L. \& Bush, P. M. (2012). Work-Related Musculoskeletal Disorders Assessment and Prevention. In: Ergonomics - A Systems Approach, I. L. Nunes (ed). pp. 1-30. InTech, 978-953-51-0601-2.

7) Nunes, I. L. \& Cruz-Machado, V. (2012). A fuzzy expert system model to deal with supply chain disturbances. Int. J. Decision Sciences, Risk and Management, 4(1/2): pp. 127-151.

8) Nuens, I. L., Figueira, S. \& Machado, V. C. (2011). Evaluation of a Supply Chain Performance Using a Fuzzy Decision Support System. Proceedings of The IEEE International Conference on Industrial Engineering and Engineering Management - IEEM2011Singapore, 6-9 Dec

9) Nunes, I. L. \& Simões-Marques, M. (2012). Applications of Fuzzy Logic in Risk Assessment - The RA X Case. In: Fuzzy Inference System - theory and applications, M. F. Azeem (ed). pp. 22-40. InTech, 978-953-510525-1.

10) Zadeh, L. A. (1965). Fuzzy sets. Information and Control, 8(3): pp. 338-353.

11) Zadeh, L. A. (1975a). The concept of a linguistic variable and its application to approximate reasoning-part I. Information Sciences, 8(3): pp. 199-249.

12) Zadeh, L. A. (1975b). The concept of a linguistic variable and its application to approximate reasoning-part II. Information Sciences, 8(4): pp. 301-357.

13) Zadeh, L. A. (1975c). The concept of a linguistic variable and its application to approximate reasoning-part III. Information Sciences, 9(1): pp. 43-80.

14) Zadeh, L. A. (1996). Fuzzy Logic = Computing with words. IEEE Transactions on Fuzzy Systems, 4(2): pp. 103-111.

Paper sent to revision: 29.08.2012.

Paper ready for publication: 26.09.2012. 